\title{
Contextual control of extinguished conditioned performance in humans
}

Citation for published version (APA):

Havermans, R. C., Keuker, J., Lataster, T., \& Jansen, A. T. M. (2005). Contextual control of extinguished conditioned performance in humans. Learning and Motivation, 36(1), 1-19.

https://doi.org/10.1016/j.Imot.2004.09.002

Document status and date:

Published: 01/01/2005

DOI:

10.1016/j.Imot.2004.09.002

Document Version:

Publisher's PDF, also known as Version of record

Document license:

Taverne

Please check the document version of this publication:

- A submitted manuscript is the version of the article upon submission and before peer-review. There can be important differences between the submitted version and the official published version of record.

People interested in the research are advised to contact the author for the final version of the publication, or visit the DOI to the publisher's website.

- The final author version and the galley proof are versions of the publication after peer review.

- The final published version features the final layout of the paper including the volume, issue and page numbers.

Link to publication

\footnotetext{
General rights rights.

- You may freely distribute the URL identifying the publication in the public portal. please follow below link for the End User Agreement:

www.umlib.nl/taverne-license

Take down policy

If you believe that this document breaches copyright please contact us at:

repository@maastrichtuniversity.nl

providing details and we will investigate your claim.
}

Copyright and moral rights for the publications made accessible in the public portal are retained by the authors and/or other copyright owners and it is a condition of accessing publications that users recognise and abide by the legal requirements associated with these

- Users may download and print one copy of any publication from the public portal for the purpose of private study or research.

- You may not further distribute the material or use it for any profit-making activity or commercial gain

If the publication is distributed under the terms of Article $25 \mathrm{fa}$ of the Dutch Copyright Act, indicated by the "Taverne" license above, 


\title{
Contextual control of extinguished conditioned performance in humans ${ }^{\text {is }}$
}

\author{
Remco C. Havermans*, Jantien Keuker, Tineke Lataster, \\ Anita Jansen
}

Faculty of Psychology, Experimental Psychology, Maastricht University, Maastricht, The Netherlands

Received 5 February 2003; received in revised form 10 September 2004

Available online 15 December 2004

\begin{abstract}
Animal research has shown that extinguished conditioned performance is modulated by the environmental context in which extinction treatment has occurred. When the conditioned stimulus is presented outside the extinction context, conditioned responding is renewed. In two experiments, whether a renewal effect can also be found in humans was investigated. In Experiment 1, a renewal effect was observed, although the effect was small and far from complete. In Experiment 2, a more substantial renewal effect was observed. The extent to which this effect occurred depended on the degree to which context was manipulated. In a third experiment, the exact nature of the observed renewal effect was examined. Results indicated that, as opposed to animals, the extinction context does not modulate extinguished conditioned responding in humans.
\end{abstract}

(C) 2004 Elsevier Inc. All rights reserved.

Keywords: Context; Extinction; Humans; Renewal

\footnotetext{
We thank Helena Matute and Mark Bouton for providing comments on an earlier version of this article, and Pauline Dibbets for helpful discussions on the topic. Further, we thank Willam Roberts for pointing out the potential role of cognitive processing in the present pattern of findings.

* Corresponding author.

E-mail address: r.havermans@psychology.unimaas.nl (R.C. Havermans).
} 
The renewal effect is one of the most important and relatively recent findings in the field of associative learning. Renewal refers to the effect in which conditioned performance is renewed after an extinction treatment. In 1979, Bouton and Bolles conducted three experiments investigating the contextual control of extinguished conditioned performance in rats, using a conditioned suppression procedure. They found that when rats received extinction treatment in an environmental context different from the context in which these rats had previously received training, presenting the conditioned stimulus (CS) in the original training context at test renewed conditioned suppression. It has been shown that this effect cannot be attributed to the extinction context acquiring a direct inhibitory association with the unconditioned stimulus (US) (see Bouton \& Peck, 1989). Rather, it seems that during extinction the CS becomes endowed with an inhibitory meaning modulated by the environmental context in which the extinction treatment has taken place. The CS has thus acquired an ambiguous meaning, as it both predicts the occurrence and the absence of the US. The meaning of the CS is disambiguated by contextual information. When the CS is presented within the extinction context, the inhibitory CS-no US association is retrieved. Context specificity of learned performance thus occurs in situations in which the CS has acquired such an ambiguous meaning (but see Hall \& Honey, 1990; Maes, Havermans, \& Vossen, 2000). In a counterconditioning preparation, the CS also acquires an ambiguous meaning. The second learned association then comes under contextual control, whereas the first learned meaning of the CS generalizes across environmental contexts (see Bouton, 1994a). This implies that presentation of the CS outside the extinction context should lead to renewal of the conditioned response, whether or not the CS is presented in the original training environment. It has repeatedly been shown in animal research that the renewal effect is not merely restricted to the re-presentation of the CS in the original training context (see Bouton, 1993, 1994b). The renewal effect thus demonstrates that extinction is not the unlearning of an excitatory association as more traditional theories of associative learning predict (e.g., Rescorla \& Wagner, 1972; see also Rescorla, 2001).

The renewal effect can be understood in terms of an interference effect, in which there is interference between different outcomes when predicted by a single CS. In other words, when two distinct outcomes are predicted by the same cue at some point in time and one of these outcomes is more strongly predicted by the cue, this will interfere with responding to the other outcome. Similarly, interference between cues is observed when they predict the same outcome. An example of such cue interference concerns the blocking effect, in which learning that a cue predicts a specific outcome interferes with learning that a second cue predicts the same outcome (Kamin, 1969). Recent studies in humans reveal that a second learned association can interfere with the original association when these associations share the same outcome (Matute \& Pineño, 1998). More recently, Pineño and Matute (2000) demonstrated interference in human subjects between outcomes when two sequentially learned associations shared the same predicting cue, and interference between cues when two sequentially learned associations shared the same outcome. Furthermore, the activation of a specific association appeared to rely heavily on contextual information, which is in agreement with Bouton's conceptualization of the contextual control of conditioned 
performance (Bouton, 1993). However, in this study, context was manipulated in an explicit manner, instructing the participants beforehand that certain cues could predict different outcomes according to the context in which these cues were presented. García-Gutiérrez and Rosas (2003) recently also found some indication of a renewal effect in humans. In this study, participants had to predict the occurrence of different symptoms of gastric illness after the intake of different chemically synthesized food items. Participants received demonstrations of files of persons having consumed different food items within a specific restaurant (X or $\mathrm{Y})$. It was found that the initially learned cue-outcome associations were retrieved in acquisition context $\mathrm{X}$ after an interference procedure in context Y. Although this effect certainly resembles renewal of conditioned performance in animals, context changes were established through description rather than experience, as is the case in animal studies on the contextual control of extinction.

Apparently, renewal is a robust effect, which tends to occur in both animals and humans, although the renewal effect has not been studied that extensively in humans as of yet. In a first experiment, the primary question of interest was whether a renewal effect could be observed in humans, similar to a renewal effect observed in animal studies, using a more implicit context manipulation than in the studies of Pineño and Matute (2000) and of García-Gutiérrez and Rosas (2003). A second experiment involved the investigation of factors affecting the potential contextual control of extinguished conditioned performance in humans. One important factor is the degree to which a context change is manipulated. Thomas, Larsen, and Ayres (2003) demonstrated that renewed conditioned fear responding in rats using an ABA renewal paradigm decreased as the $\mathrm{A}$ and $\mathrm{B}$ contexts became more similar. In a third experiment, the exact nature of the renewal effect in humans was investigated.

The questions of whether a renewal effect occurs in humans and to what degree such an effect depends on context manipulation are relevant as the renewal effect holds great implications for the behavioral treatment of human psychopathology. One form of such a behavioral treatment is cue exposure therapy, which is based on the principle of extinction. It is assumed that certain cues elicit responses, which constitute or lead to the expression of psychopathological behavior and that repeated exposure to such cues will lead to the extinction of the abnormal behavior. As Bouton and Swartzentruber (1991) have argued, animal research concerning the contextual control of conditioned responding shows that this particular assumption may be false. Gaining insight into what degree a renewal effect occurs in humans could thus be of great benefit to clinical research concerning cue exposure therapy.

\section{Experiment 1}

In Experiment 1, it was investigated whether a renewal effect can also occur in human subjects using an ABA renewal paradigm. Three different groups of participants received conditioning and a subsequent extinction treatment. One group received conditioning and extinction against the same background stimuli (context A). A second group received the extinction treatment against background stimuli 
(context B) different from the acquisition context A. A third group received conditioning trials in context $\mathrm{A}$ and were subsequently exposed to context $\mathrm{B}$, but no extinction trials were presented in context B. Contextual control of extinguished performance should be apparent in the participants having received the acquisition phase and the extinction treatment in different contexts.

\section{Method}

\section{Participants}

Forty-eight undergraduate students from Maastricht University participated in the present experiment (14 men and 34 women with a mean age of 20 years). Participants were randomly assigned to one of three different groups of equal size $(n=16)$ : Group AAA, received acquisition and extinction in the same context; group ABA, received acquisition and extinction in different contexts; and group NE, received conditioning trials in context A but no extinction in context B. Participants received course credits upon completion of the experimental task.

\section{Procedure and design}

A conditioned suppression task was employed to investigate whether renewal can occur in humans and was largely based on the task designed by Arcediano, Ortega, and Matute (1996). In this task, participants played a video game in which they had to prevent an impending invasion of hostile "Martians." This video game was programmed in Experimental Run Time System (Berisoft, Germany) and run on an IBM-compatible personal computer. Participants completed the task individually in a quiet research room with the experimenter monitoring performance.

Pretraining. Participants first received the verbal instruction from the experimenter that they would have to defend the planet Earth from the Martians by preventing the Martians from landing on the planet. They could do so by firing at the Martians with a laser gun (by pressing the spacebar on the keyboard). In the pretraining phase, Martians were presented every $600 \mathrm{~ms}$, one by one flying across the computer screen from the top center of the screen downward in $300 \mathrm{~ms}$. If one fired before the next Martian was displayed, an explosion instead of the Martian would be presented. Martians and explosions measured approximately $1.5 \mathrm{~cm}^{2}$. In Fig. 1, the pictures representing the Martians and the explosion are displayed. The pretraining phase consisted of 100 presentations of a Martian and lead to a constant, operant bar pressing response. Participants received the following additional instructions on screen (translated from Dutch):

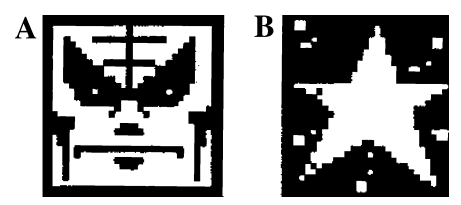

Fig. 1. Picture of a Martian (A) and an explosion (B) as used in the present study. 
"In this task, you need to prevent Martians from invading the planet. Approximately every half second, a Martian will try to land. In order to destroy the Martians you will have to shoot them with your laser gun (by pressing the spacebar) BEFORE they can see you, that is just before a new Martian appears on screen. Do not fire too early, because you have only one shot per Martian. If you successfully destroy a Martian, an explosion instead of a Martian will appear on screen. At the end of this game you will attain feedback on the percentage of Martians you have destroyed.

THE PLANET IS COUNTING ON YOU! DON'T LET THEM LAND!!”

Training. In the training phase, participants were told that the Martians have developed an antilaser-shield and that firing the laser gun while the shield is activated will reflect the shot disabling the gun for $4.8 \mathrm{~s}$. The Martians invade the planet at twice the speed while the laser gun is out of order. The antilaser-shield was displayed as a white intermittent flashing of the background screen color (white/black alternating every $100 \mathrm{~ms}$ ) with a duration of $600 \mathrm{~ms}$. First, the experimenter demonstrated in four trials what the antilaser-shield looked like and what would happen if one fires during presentation of the antilaser-shield. Next, the participant had to perform the task for himself, but now a $500 \mathrm{~Hz}$ computer generated tone immediately preceded the presentation of the antilaser-shield with a duration of $600 \mathrm{~ms}$. The tone thus functioned as a CS and the antilaser-shield as a US. All participants received the following instructions (translated from Dutch):

"The Martians have now developed an antilaser-shield. You have to keep firing your laser in order to prevent them from landing. BUT BE CAREFUL, because when you fire when the shield is activated, your shot will be reflected, disabling your laser gun. Immediately, thousands of Martians will land safely, without any interference. You can recognize the activation of the shield by a WHITE intermittent FLASHING of the background.

Remember! It only takes one shot when the antilaser-shield is activated, and the Martians will invade successfully!!"

The training phase consisted of 20 conditioning trials with a variable intertrial interval (ITI), varying around a mean of $6 \mathrm{~s}$ (ranging from 4.8 to $7.2 \mathrm{~s}$ ). The first and every fourth trial functioned as assessment trials in which the tone lasted for $3 \mathrm{~s}$. These longer presentations of the CS allowed for a more sensitive measurement of conditioned suppression (see also Arcediano et al., 1996). Conditioned suppression was measured by calculating the suppression ratio, $X / X+Y$, on the assessment trials with $X$ being the number of bar presses during the 3-s CS and $Y$ being the number of bar presses during the 3-s period directly preceding onset of the CS. Conditioning was considered successful when participants had a suppression ratio lower than 0.3 on the last training trial.

One could argue that the term conditioned suppression does not apply to the present task. In animal research, conditioned suppression refers to a conditioned emotional response. In rats, the suppression response consists partly of freezing, a fear-motivated reaction. In the present task, the suppression response is not a conditioned emotional response because it is not fear driven. The Martian task might be described instead as an anticipated punishment procedure. Responses during the presentation of the white intermittent flashing of the background will be punished. In 
Table 1

Design of Experiment 1

\begin{tabular}{|c|c|c|c|c|}
\hline Group & Pretraining & Training & Extinction & Test \\
\hline AAA & A & $\mathrm{A}[\mathrm{CS}-\mathrm{US}]$ & $\mathrm{A}[\mathrm{CS}]$ & $\mathrm{A}[\mathrm{CS}]$ \\
\hline $\mathrm{ABA}$ & A & $\mathrm{A}[\mathrm{CS}-\mathrm{US}]$ & $\mathrm{B}[\mathrm{CS}]$ & $\mathrm{A}[\mathrm{CS}]$ \\
\hline NE & A & $\mathrm{A}[\mathrm{CS}-\mathrm{US}]$ & B & $\mathrm{A}[\mathrm{CS}]$ \\
\hline
\end{tabular}

Note. A and B represent the background screen color (blue versus red, counterbalanced) of the "Martians" task.

anticipating this punishment, participants eventually suppress their responses not only during presentation of the white flash, but also during presentation of the predictive tone stimulus. Therefore, the suppression of bar pressing that occurs while the predictive cue is present can be regarded as an anticipatory reaction to the passive avoidance of the white flash that is required by the game instructions. Thus, the term conditioned suppression, as used throughout this article, specifically refers to suppression of operant responding due to anticipated punishment and not to conditioned emotional responding.

Extinction. Directly following training, participants from groups AAA and ABA received 20 extinction trials with the first and every fourth extinction trial as assessment trials and the same variable ITI as during the training phase. Extinction trials consisted of presentation of the CS alone. Participants from group NE received no extinction trials (i.e., no CSs and USs were presented), but they had to destroy the Martians for the same amount of time as the participants from the other two groups during extinction.

Extinction test. At test, each participant received eight extinction trials with the first and every fourth trial as assessment trials and the same variable ITI as during the training and extinction phase. The test phase immediately followed the extinction treatment.

Context manipulation. An important difference between the original task by Arcediano et al. (1996) and the task used in the present study is that the invading Martians do not accumulate on screen during the game. This was done deliberately, because in the present study context was manipulated by changes in background screen color. The accumulation of Martians on screen would have negatively affected context salience. Group AAA received the different phases of the task against one and the same background screen color, blue or red counterbalanced. Group ABA received pretraining and training against a background $\mathrm{A}$ (blue or red counterbalanced), extinction against another background B (red when A had been blue, and vice versa), and the test against background A. Group NE received the same context manipulation as group ABA. The experimental design is displayed in Table 1.

\section{Results and discussion}

For all reported analyses, a level of significance of $p<.05$ was used throughout the article, unless stated otherwise. In Fig. 2, the mean suppression ratios per group and per assessment trial, as measured throughout the experiment, are displayed. 


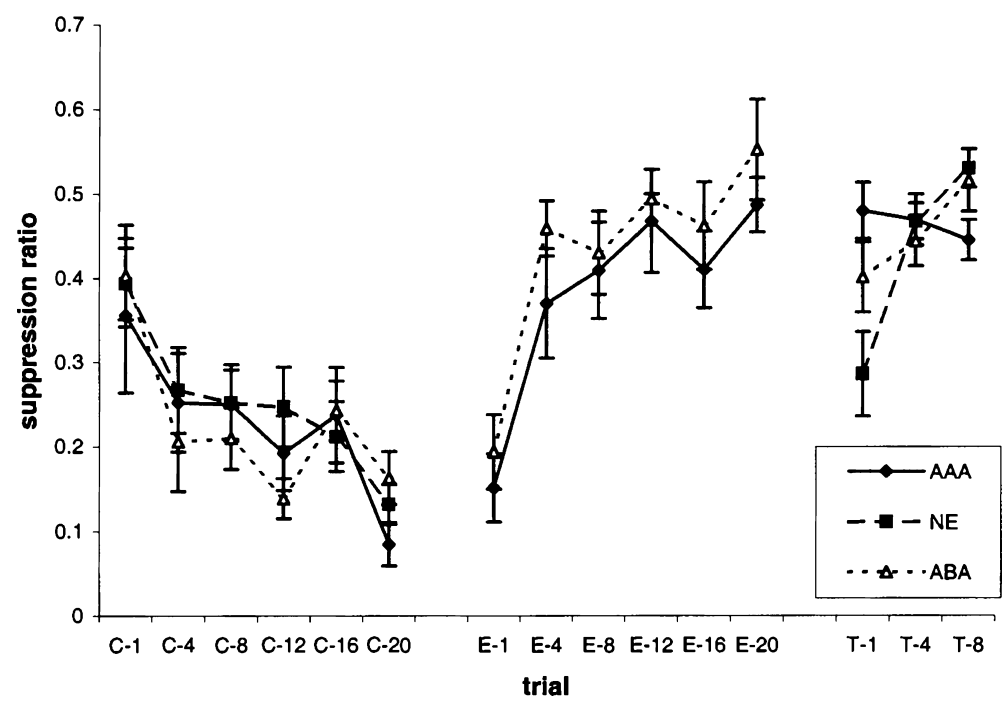

Fig. 2. Mean suppression ratio per assessment trial for each of the three groups, minus the participants who failed to meet the conditioning criterion. $\mathrm{C}$ stands for conditioning, $\mathrm{E}$ stands for extinction, and $\mathrm{T}$ stands for test. Error bars represent standard errors of the means.

\section{Conditioning}

Conditioning was regarded as successful when a suppression ratio lower than 0.3 was observed on the last training trial. Although most participants met this criterion, 12 participants failed to do so; four participants from group AAA, six participants from group ABA, and two participants from group NE. The data from these participants were thus excluded from the following analyses.

To test whether the training phase led to a gradual increase in the strength of conditioned suppression, a two-way analysis of variance (ANOVA) was conducted with Trial $(1,4,8,12,16$, or 20) as a within-subject factor, Group (AAA, ABA, or NE) as a between-subjects factor, and suppression ratio calculated over the six assessment trials during the training phase as the dependent variable. A main effect for Trial was found, $F(5,100)=7.91$. No other effects were found, $F$ s $<1$. These results indicate that training led to a progressive increase in the strength of conditioned suppression across groups.

\section{Extinction}

To test whether the extinction treatment led to the gradual extinction of conditioned suppression, a two-way ANOVA was run with Trial $(1,4,8,12,16$, or 20) as a within-subject factor, Group (AAA versus ABA) as a between-subjects factor, and suppression ratio calculated over the six extinction assessment trials as the dependent variable. A main effect of Trial was found, $F(5,100)=13.69$. No Trial $\times$ Group interaction effect was found, $F(5,100)=0.15$. No effect of Group was found, $F(1,20)=1.98$. These results indicate that the extinction treatment led to the extinction of conditioned suppression in both groups. 


\section{Renewal}

To test for a potential renewal effect, a two-way ANOVA was conducted with Trial (the last extinction trial versus the first test trial) as a within-subject factor, Group (AAA versus ABA) as a between-subjects factor, and suppression ratio calculated over the last extinction assessment trial and the first test assessment trial as the dependent variable. A trend towards an effect for Trial was found, $F(1,20)=3.75$, $p<.10$. A trend towards a Trial $\times$ Group interaction effect was found, $F(1,20)=3.14$, $p<.10$. No effect of Group was found, $F<1$.

Planned comparisons, analyzing conditioned suppression on the first test assessment trial, revealed a significant difference in suppression ratio for the first test trial between group AAA and group NE, $F(1,25)=9.75$. No difference in suppression ratio on the first test trial between group AAA and ABA was found, $F(1,21)=2.25$, and no difference was found in suppression ratio on the first test trial between groups $\mathrm{ABA}$ and NE, $F(1,23)=2.77$.

The present results of interest indicate that the participants in group ABA showed no direct evidence for renewal of conditioned suppression. The results, however, display a clear trend towards a renewal effect. Furthermore, if no renewal had occurred at all, one would expect that the suppression ratio on the first test trial for the participants in group ABA would have differed significantly from conditioned performance on the first test trial for the participants in group NE. The fact that this was not the case indicates that some renewal of conditioned suppression may have taken place, although this renewal effect is admittedly small.

Although the experimenter monitored performance of the participants throughout the experiment, no feedback was provided about their performance by the experimenter. This may have led to insufficient learning of the operant response and the subsequent finding that $25 \%$ of all the participants failed to meet the conditioning criterion. This loss of data may have negatively affected the power of the statistical analyses and caused a type II error. An alternative explanation for the absence of a substantial renewal effect in this experiment might be that the context manipulation was not strong enough; that is, the participants did not perceive the changes in background screen color as a fundamental change from one context to another. It is important to note that the Martians displayed in the task were the same color throughout the entire experiment (i.e., white), and thus formed a common element between the different experimental contexts. It is possible that this common element reduced the discrepancy between contexts $\mathrm{A}$ and $\mathrm{B}$, hence promoting generalization of extinguished behavior. This notion then leads to the prediction that a more complete context manipulation should lead to a more substantial renewal effect.

\section{Experiment 2}

In Experiment 1, no substantial renewal was observed. It is suggested that this may be due to an incomplete context manipulation. Indeed animal research has 
shown that renewal of extinguished conditioned performance depends on the degree to which the test context perceptually differs from the extinction context (Thomas et al., 2003). Therefore, a second experiment was conducted in an attempt to replicate the results from Experiment 1 and to investigate whether the degree to which a context switch is established determines the extent to which a potential renewal effect can be observed.

\section{Method}

\section{Participants}

A total of 48 undergraduate students from Maastricht University were recruited for participation in the present experiment (10 men and 38 women with a mean age of 21 years). Participants were randomly assigned to four different groups (AAA, $\mathrm{ABA}, \mathrm{ABA}+$, or $\mathrm{NE})$ of equal size $(n=12)$. Participants received course credits upon completion of the task.

\section{Procedure and design}

The design for Experiment 2 is displayed in Table 2. The same procedure was used as described in Experiment 1. Context was again manipulated by changes in background screen color; blue versus yellow. However, in group ABA+, switches in background screen color were additionally accompanied by changes in the color of the invading Martians (white when the background color is blue, and red when the background color is yellow). In group ABA, the color of the Martians (white or red) displayed during extinction would remain the same during test, despite a change in background color.

In Experiment 1, participants indicated after the experiment that they found the task to be rather difficult. Indeed, the participants who failed to meet the conditioning criterion showed highly irregular responding (i.e., shooting Martians) throughout the entire experiment. Feedback may improve performance during the pretraining phase and hence lead to better performance in the following phases of the task. Therefore, in the present experiment, the experimenter monitored performance during the pretraining phase and gave concurrent verbal feedback upon performance during this phase. The experimenter did not give any feedback during the rest of the experiment.

Table 2

Design of Experiment 2

\begin{tabular}{lllll}
\hline Group & Pretraining & Training & Extinction & Test \\
\hline AAA & $\mathrm{Aa}$ & $\mathrm{Aa}[\mathrm{CS}-\mathrm{US}]$ & $\mathrm{Aa}[\mathrm{CS}]$ & $\mathrm{Aa}[\mathrm{CS}]$ \\
$\mathrm{ABA}+$ & $\mathrm{Aa}$ & $\mathrm{Aa}[\mathrm{CS}-\mathrm{US}]$ & $\mathrm{Bb}[\mathrm{CS}]$ & $\mathrm{Aa}[\mathrm{CS}]$ \\
$\mathrm{ABA}$ & $\mathrm{Aa}$ & $\mathrm{Aa}[\mathrm{CS}-\mathrm{US}]$ & $\mathrm{Bb}[\mathrm{CS}]$ & $\mathrm{Ab}[\mathrm{CS}]$ \\
NE & $\mathrm{Aa}$ & $\mathrm{Aa}[\mathrm{CS}-\mathrm{US}]$ & $\mathrm{Bb}$ & $\mathrm{Aa}[\mathrm{CS}]$ \\
\hline
\end{tabular}

Note. A and B represent the background screen color (blue versus yellow, counterbalanced) of the "Martians" task, whereas a and b represent the color of the Martians (or explosions) (white versus red, counterbalanced). 


\section{Results and discussion}

The results in Fig. 3 display the mean suppression ratio per assessment trial, as measured throughout the experiment, and per group.

\section{Conditioning}

Conditioning again was regarded as successful when a suppression ratio lower than 0.3 was observed on the last training trial. A total of three participants failed to meet this criterion; one participant from group AAA, one participant from group $\mathrm{ABA}+$, and one participant from group NE. The data from these participants were thus excluded from the following analyses.

To test whether the training phase rendered a gradual increase in conditioned suppression, a two-way ANOVA was conducted with Trial $(1,4,8,12,16$, or 20) as a within-subjects factor, Group (AAA, ABA, ABA+, or NE) as a between-subjects factor, and suppression ratio calculated over the six assessment trials during the training phase as the dependent variable. A main effect for Trial was found, $F(5,220)=127.58$. No Trial $\times$ Group interaction effect was found, $F(15,220)=$ 1.30 , and no effect of Group was found, $F<1$. These results indicate that training led to a progressive increase in the strength of conditioned suppression across groups.

\section{Extinction}

To test whether the extinction treatment led to the successful extinction of conditioned suppression, a two-way ANOVA was run with Trial $(1,4,8,12,16$, or 20$)$ as a within-subjects factor, Group (AAA, ABA, or ABA+) as a between-subjects factor,

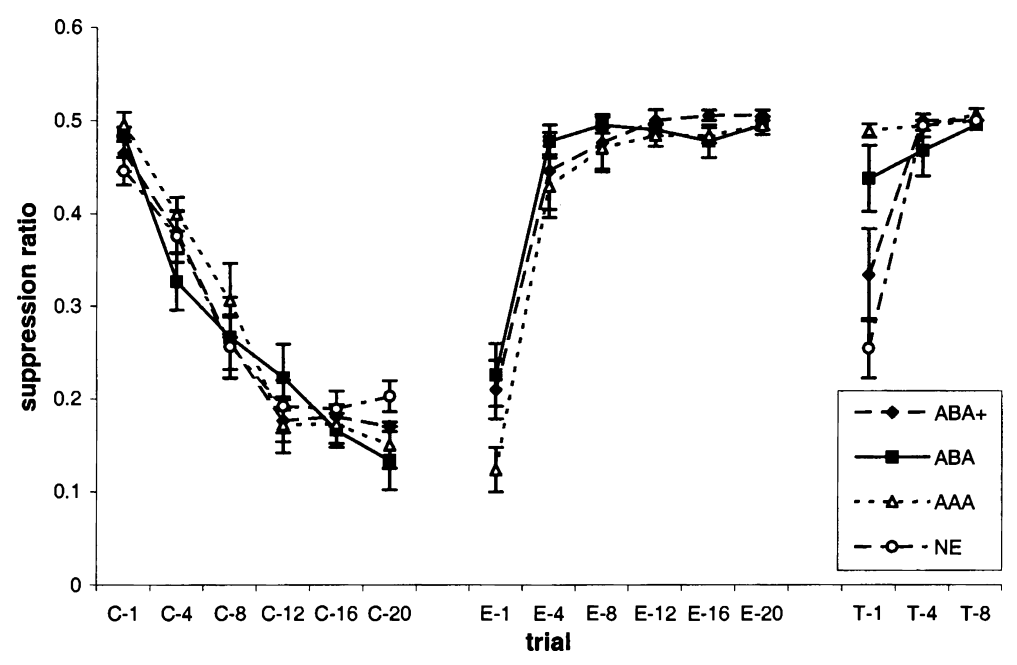

Fig. 3. Mean suppression ratio per assessment trial for each of the four different groups, minus the participants who failed to meet the conditioning criterion. C stands for conditioning, E stands for extinction, and $\mathrm{T}$ stands for test. Error bars represent standard errors of the means. 
and the suppression ratio calculated over the six extinction assessment trials as the dependent variable. A main effect of Trial was found, $F(5,155)=119.64$. No Trial $\times$ Group interaction effect was found, $F(10,155)=1.39$, and no effect of Group was found, $F(2,31)=1.77$. These results indicate that the extinction treatment led to the successful extinction of conditioned suppression.

\section{Renewal}

To test for a potential renewal effect, a two-way ANOVA was conducted with Trial (the last extinction trial versus the first test trial) as a within-subjects factor, Group (AAA, ABA, or ABA+) as a between-subjects factor, and suppression ratio calculated over the last extinction assessment trial and the first test assessment trial as the dependent variable. An effect of Trial was found, $F(1,31)=13.34$, a Trial $\times$ Group interaction was found, $F(2,31)=5.16$, and an effect of Group was found, $F(2,31)=4.17$. These results clearly imply that a renewal effect has occurred. The significant Trial $\times$ Group interaction also indicates that this renewal effect may have specifically occurred in one particular group. Post hoc $t$ tests, testing each group separately for a potential renewal effect by comparing conditioned suppression on the last extinction trial with conditioned suppression on the first test trial per group revealed that renewal was evident in group $\mathrm{ABA}+, t(10)=3.32$. No direct evidence for a renewal effect was found for group $\mathrm{ABA}, t(11)=1.57$, and no renewal was found for group AAA, $t(10)=0.56$.

Planned comparisons, analyzing conditioned suppression on the first test assessment trial, revealed a significant difference in suppression ratio on the first test trial between groups ABA+ and AAA, $F(1,21)=9.55$. A difference was found between ABA and NE, $F(1,22)=14.53$. A significant difference was found between groups AAA and NE, $F(1,21)=51.65$. No difference was found in suppression ratio on the first test trial between groups $\mathrm{ABA}+$ and $\mathrm{NE}, F(1,21)=1.79$. No difference was found in suppression ratio between groups AAA and ABA, $F(1,22)=1.86$. No significant difference in suppression ratio for the first test trial between group ABA+ and group ABA was found, $F(1,22)=2.96$.

The results of interest indicate that, as in Experiment 1, group ABA showed a minor trend towards a renewal effect. However, renewal was far more substantial for group $\mathrm{ABA}+$ that received a more complete context manipulation than for group ABA. Conditioned suppression at test for the participants in group ABA+ did not differ from the degree of conditioned suppression by the participants from group NE who had received no extinction treatment. It was thus shown that renewal can be observed in humans and that in accordance with the animal literature, this depended on the extent to which the test context differed from the extinction context.

Although a strong renewal effect was observed in this experiment, it remains unclear whether the observed return of conditioned responding after extinction is due to the extinction context modulating the activation of the inhibitory meaning of the CS. The present renewal effect can be explained by arguing that a context switch will lead to generalization decrement and thus to a loss of inhibited or excitatory responding. To test whether the initial context switch from acquisition context to the 
extinction context had led to a loss of conditioned suppression for participants in groups $\mathrm{ABA}$ and $\mathrm{ABA}+$ as opposed to the participants in group AAA, a two-way ANOVA was conducted with Trial (the last conditioning assessment trial versus the first extinction trial) as a within-subjects factor, Group (ABA, ABA+, or AAA) as a between-subjects factor, and suppression ratio as the dependent variable. No main effect for Trial was found, $F(1,31)=3.66$, and no effect of Group was found, $F(2,31)=1.60$. However, a significant Trial $\times$ Group interaction effect was found, $F(2,31)=3.50$, indicating that there may have been some generalization decrement that was limited to a specific group. To test this suggestion, post hoc $t$ tests were conducted comparing conditioned suppression on the last conditioning trial and the first extinction trial within each group (i.e., groups $\mathrm{ABA}, \mathrm{ABA}+$, and $\mathrm{AAA}$ ). No difference in conditioned suppression was found for group ABA, $t(10)=1.27$, but a significant difference in suppression was found for the participants in group $\mathrm{ABA}+, t(11)=3.13$. As expected, no difference in conditioned suppression was found for group AAA, $t(10)<1$. These results imply that some generalization decrement occurred and that the strong renewal effect observed for the participants in group ABA+ can at least partially be ascribed to a context A-CS configural cue being associated with the US during the acquisition phase.

\section{Experiment 3}

In Experiments 1 and 2, evidence for renewed conditioned responding after an extinction treatment in humans was found. Although this suggests that as in animals, the CS acquires an ambiguous meaning that is modulated by the environmental context, the observed renewal effect can also be explained by stating that the CS and the acquisition context taken together form a configural stimulus that is associated with the US (Pearce, 1987). This should lead to renewed conditioned responding after an extinction treatment in context B when the CS is presented in the original conditioning context $\mathrm{A}$. Another alternative explanation is that during the extinction phase, the extinction context B becomes an inhibitory stimulus. In this case, no extinction of conditioned responding to the CS will have taken place, allowing for the return of conditioned responding when the CS is presented outside the extinction context. Therefore, a third experiment was conducted to replicate and further examine the exact nature of the present observed renewal effect in humans.

\section{Method}

\section{Participants}

A total of 54 undergraduate students from Maastricht University were recruited for participation in the present experiment (16 men and 38 women with a mean age of 20 years). Participants were randomly assigned to three different groups (ABA, $\mathrm{ABB}$, or $\mathrm{ABC})$ of equal size $(n=18)$. Participants received course credits upon completion of the task. 
Table 3

Design of Experiment 3

\begin{tabular}{llllll}
\hline Group & Pretraining & Training & Extinction & Summation test & Renewal test \\
\hline ABA & A & A $[\mathrm{T}-\mathrm{US} / \mathrm{V}-\mathrm{US}]$ & $\mathrm{B}[\mathrm{T}-$ noUS $]$ & $\mathrm{B}[\mathrm{V}]$ & $\mathrm{A}[\mathrm{T}]$ \\
ABB & A & $\mathrm{A}[\mathrm{T}-\mathrm{US} / \mathrm{V}-\mathrm{US}]$ & $\mathrm{B}[\mathrm{T}-$ noUS $]$ & $\mathrm{B}[\mathrm{V}]$ & $\mathrm{B}[\mathrm{T}]$ \\
ABC & A & $\mathrm{A}[\mathrm{T}-\mathrm{US} / \mathrm{V}-\mathrm{US}]$ & $\mathrm{B}[\mathrm{T}-$ noUS $]$ & $\mathrm{B}[\mathrm{V}]$ & $\mathrm{C}[\mathrm{T}]$ \\
\hline
\end{tabular}

Note. A, B, and C represent the different experimental contexts of the "Martians" task (blue background with orange Martians, red background with white Martians, or a yellow background with purple Martians counterbalanced). $\mathrm{T}$ and $\mathrm{V}$ represent the auditory and visual CS, respectively.

\section{Procedure and design}

The design for Experiment 3 is displayed in Table 3. The same procedure was used as described in Experiments 1 and 2. Context was manipulated by changes in background screen color and the color of the Martians; a blue background with orange Martians, a yellow background with purple Martians, or a red background with white Martians. During the acquisition phase, two distinct CSs were paired with the US. The CSs comprised an auditory stimulus $\mathrm{T}$ as described in the previous experiments and a visual stimulus $\mathrm{V}$. This latter stimulus consisted of the $600 \mathrm{~ms}$ presentation of three vertically spaced cyan colored squares of approximately $3 \mathrm{~cm}^{2}$ at the center of the screen. The acquisition phase consisted of 40 trials; 20 acquisition trials for each CS. As in the previous experiments, the first and every fourth trial of each CS were assessment trials in which the CS was presented for $3 \mathrm{~s}$. The order of trials during this acquisition phase was determined randomly with the limitation of no more than three consecutive trials of the same type and was the same for all participants.

All participants received an initial context switch, from the acquisition phase in context A to extinction in context B. If conditioned responding is context specific, this context switch should lead to a loss of responding due to generalization decrement. The extinction phase consisted of 12 trials of nonreinforced exposure to $\mathrm{T}$, with the first and every fourth trial functioning as assessment trials. After the extinction of responding to $T$, a summation test followed which comprised a single nonreinforced 3-s presentation of $\mathrm{V}$ in context $\mathrm{B}$. If the extinction context $\mathrm{B}$ acquired an inhibitory association with the US, one would expect attenuated conditioned responding to $\mathrm{V}$ on the summation test.

The summation test was followed by a single 3-s nonreinforced presentation of $\mathrm{T}$ in either the original acquisition context $\mathrm{A}$ (group $\mathrm{ABA}$ ), the extinction context $\mathrm{B}$ (group $\mathrm{ABB}$ ), or in a novel context $\mathrm{C}$ (group $\mathrm{ABC}$ ), comprising the renewal test. If renewal is due to the $\mathrm{CS}$ acquiring an ambiguous meaning controlled by the extinction context, then one would expect to find renewal in both group $\mathrm{ABA}$ and $\mathrm{ABC}$, as opposed to group ABB.

\section{Results and discussion}

Fig. 4 displays the mean conditioned suppression to $\mathrm{T}$ and $\mathrm{V}$ during conditioning, the extinction phase and the summation test for all participants, regardless of group assignment. 


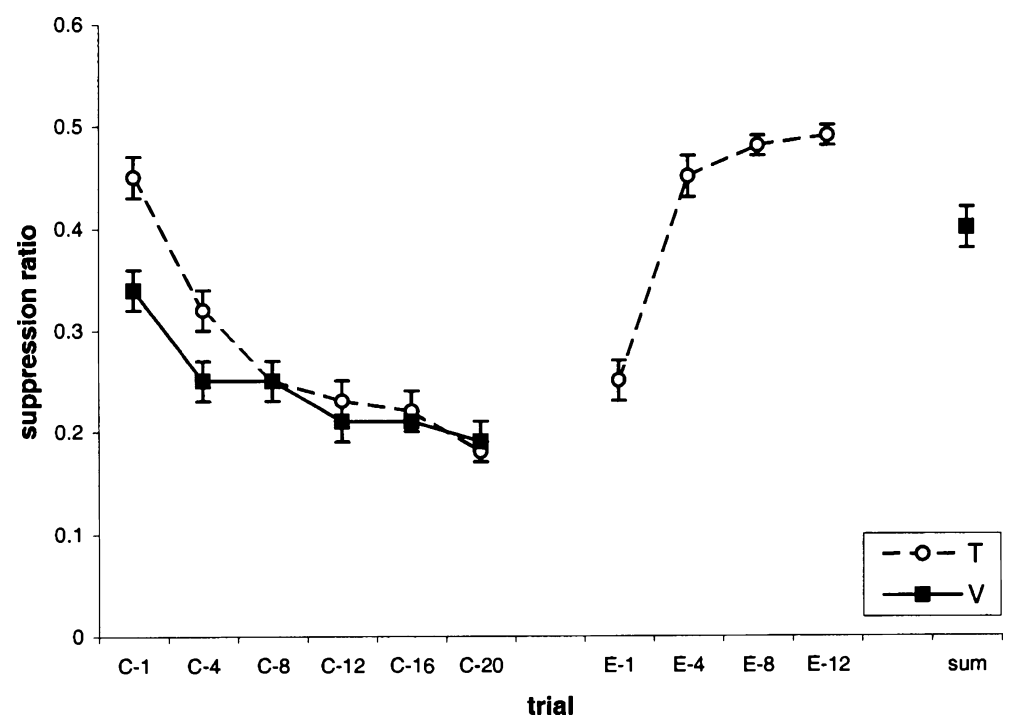

Fig. 4. Mean suppression ratio per assessment trial of the conditioning phase, the extinction phase and the summation test for all participants regardless of group assignment (minus the participants who failed to meet the conditioning criterion). $\mathrm{C}$ stands for conditioning, E for extinction, and 'sum' refers to the summation test. T and V refer to the auditory and visual CS, respectively. Error bars represent standard errors of the means.

\section{Conditioning}

Again, a conditioning criterion was used. Conditioning was considered to be successful when a suppression ratio lower than 0.3 was measured for each CS (T and V) on the last training assessment trials. A total of 16 participants failed to meet this criterion: five participants in group $\mathrm{ABA}$, five in group $\mathrm{ABB}$, and six in group $\mathrm{ABC}$. The data of these participants were excluded from further analyses.

On the data of the remaining 38 participants, a three-way ANOVA was conducted, with CS (T versus V) and Trial (conditioning assessment trials 1-6) as the within-subjects factors, Group (ABA, $\mathrm{ABB}$, or $\mathrm{ABC}$ ) as a between-subjects factor, and suppression ratio as calculated for the six conditioning assessment trials as the dependent variable. A main effect of CS was found, $F(1,35)=8.67$, indicating stronger conditioned suppression to CS V than to CS T. An effect of Trial was found, $F(5,175)=31.59$, reflecting an increase in the strength of conditioned suppression with progressive conditioning. No effect of Group was found, $F(2,35)=2.25$. A $\mathrm{CS} \times$ Trial interaction was found, $F(5,175)=5.56$, indicating a differential increase in strength of conditioned suppression between CS V and CS T. This effect can be ascribed to the fact that for each participant the first conditioning trial consisted of the reinforced presentation of $\mathrm{T}$. Therefore, the first presentation of $\mathrm{V}$ may have lead the participants to behave more cautiously than normal (expressed as suppression of the operant response) due to their prior experience with $\mathrm{T}$. No other effect was found, $F_{\mathrm{s}}<1$. 


\section{Extinction}

To test whether extinction of conditioned suppression to the tone $\mathrm{T}$ had been successful, a two-way ANOVA was conducted with Trial (extinction assessment trials 1 4 ) as a within-subjects factor, Group (ABA, ABB, or ABC) as a between-subjects factor, and conditioned suppression to the tone on the extinction assessment trials as the dependent variable. A main effect of Trial was found, $F(3,105)=64.53$, reflecting the rapid extinction of conditioned suppression to the tone T. No effect of Group was found, $F<1$, and no interaction was found, $F(6,105)=2.04$, indicating that the pattern of extinction was uniform across groups.

\section{Generalization decrement}

In the previous experiments, some generalization decrement was found, referring to the loss of conditioned responding due to a context switch after the acquisition phase. To test whether generalization decrement had occurred in the present experiment, a two-way ANOVA was conducted with conditioned suppression to $\mathrm{T}$ on the last conditioning assessment trial and the first extinction trial as a within-subjects factor and Group (ABA, ABB, or ABC) as a between-subjects factor. A main effect for Trial was found, $F(1,35)=19.59$, implying a loss of strength of conditioned suppression to $\mathrm{T}$ with the context switch from $\mathrm{A}$ to $\mathrm{B}$ due to generalization decrement. No effect of Group was found, $F(2,35)=1.57$, and no interaction was found, $F(2,35)=2.93$.

\section{Summation test}

To test whether the extinction of conditioned suppression to $\mathrm{T}$ was the result of an inhibitory context B-noUS association, a summation test was conducted following the extinction phase. In context $\mathrm{B}$, a single nonreinforced presentation of $\mathrm{V}$ comprised the summation test. Conducting a two-way ANOVA, conditioned suppression to $\mathrm{V}$ on the summation test was compared with conditioned suppression to $\mathrm{T}$ on the last extinction trial. A significant difference in conditioned suppression to $\mathrm{T}$ and $\mathrm{V}$ was found, $F(1,35)=17.46$, indicating that the extinction context did not completely inhibit conditioned suppression to V. No other effects were found, $F$ s $<1$. An additional $t$ test was conducted comparing suppression to $\mathrm{V}$ on the summation test with responding to $\mathrm{V}$ at the end of acquisition. A significant difference in conditioned suppression was found, $t(37)=10.33$, indicating a loss in conditioned suppression to $\mathrm{V}$ at the summation test. Although apparently conditioned suppression to $\mathrm{V}$ was attenuated when presented in context B, participants still showed conditioned suppression to $\mathrm{V}$ within this context, as opposed to $\mathrm{T}$. This then implies that $\mathrm{V}$ was still a potent $\mathrm{CS}$ and that context $\mathrm{B}$ alone was not controlling extinction.

\section{Renewal test}

Fig. 5 displays the mean conditioned suppression to $\mathrm{T}$ at the last extinction trial versus the renewal test for each separate group. To test whether renewal had occurred, a two-way ANOVA was conducted with Trial (the last extinction trial versus the renewal test trial) as a within-subjects factor, Group (ABA, ABB, or ABC) as a between-subjects factor, and conditioned suppression to $\mathrm{T}$ on the last extinction 


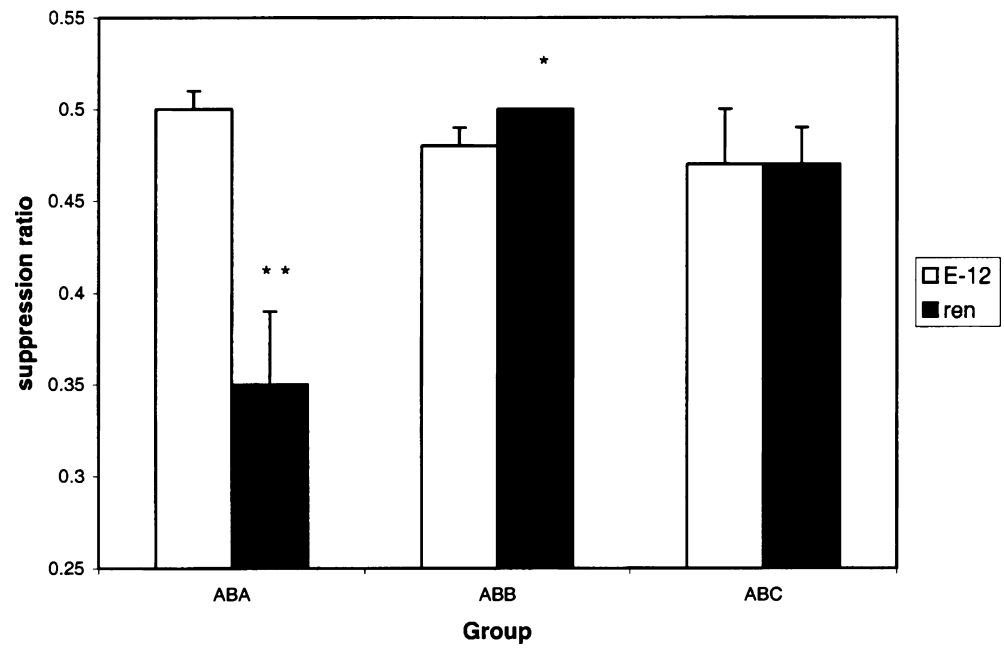

Fig. 5. Mean suppression ratio for T at the last extinction trial (E-12) and the renewal test ('ren') for each separate group plus standard errors of the means. $* p<.05 ; * * p .01$.

trial and the renewal test as the dependent variable. A main effect of Trial was found, $F(1,35)=7.52$, indicating differential conditioned responding comparing the last extinction trial with the renewal test. No effect of Group was found, $F(2,35)=3.18$, but the Trial $\times$ Group interaction proved to be significant, $F(2,35)=11.60$, implying that the effect of Trial was probably restricted to a particular group (or groups). These results are indicative of a renewal effect, as conditioned suppression appears to be stronger on the renewal test than on the last extinction trial.

Post hoc $t$ tests were conducted to examine which of the three groups showed a renewal effect. As expected, a renewal effect was apparent for participants in group $\mathrm{ABA}, t(12)=3.46$. A significant difference in conditioned suppression was also found for the participants in group ABB, $t(11)=2.35$. As can be inferred from Fig. 5, however, this difference is due to the fact that participants in this group showed less conditioned suppression to $\mathrm{T}$ at the renewal test than at the last extinction trial and thus can be ascribed to progressive extinction of conditioned suppression to T. Somewhat unexpectedly, no indication of a renewal effect was found for group $\mathrm{ABC}, t(12)<1$.

In addition, planned comparisons were conducted, comparing the groups on conditioned suppression to $\mathrm{T}$ on the renewal test. Participants in group ABA demonstrated more conditioned suppression on the renewal test than the participants in group ABB, $F(1,24)=11.33$, reflecting the return of conditioned suppression to $\mathrm{T}$ for group ABA. Participants in group ABA also showed more conditioned suppression on the renewal test when compared with group $\mathrm{ABC}, F(1,25)=7.08$. No difference in conditioned suppression to $\mathrm{T}$ on the renewal test was found between groups $\mathrm{ABB}$ and $\mathrm{ABC}, F(1,24)=2.10$.

The results indicate the renewal of extinguished performance, as in Experiments 1 and 2, but this apparent renewal effect was restricted to the acquisition context $\mathrm{A}$ (ABA paradigm). The context specific renewal effect can be explained by arguing that 
conditioned suppression to T was context specific to begin with. Such context specificity can be accounted for by presuming that the conditioning trials in context A led to the formation of a configural context A-CS stimulus being associated with the US. According to this explanation, the initial context switch should have led to generalization decrement, leading to a loss of conditioned suppression. Indeed, such generalization decrement appears to have occurred. Renewal of the CR should thus be expected only to occur when the $\mathrm{CS}$ is presented in the original acquisition context $\mathrm{A}$, but not in a novel context $\mathrm{C}$.

\section{General discussion}

In the present study, the question of whether renewal of conditioned performance can be demonstrated in humans was investigated using a behavioral conditioned suppression preparation. The results from the three experiments indicate that renewal can indeed be observed in humans. As in animal research, the degree of renewal depends on the degree of the context switch, the larger the context switch the larger the renewal, as was demonstrated in Experiment 2 (see also Thomas et al., 2003). However, in contrast with animal research, the results of Experiment 3 indicate that such renewal was restricted to the ABA renewal paradigm. When the CS T was presented at test in a novel context $\mathrm{C}$, no renewal of extinguished conditioned suppression occurred. One could argue that the absence of a clear $\mathrm{ABC}$ renewal effect results from the extinction context $\mathrm{B}$ acquiring a direct inhibitory association with the US during extinction treatment. However, responding to both CS T and CS V in extinction context B should then have been attenuated to an equal extent. This was not the case. After complete extinction of conditioned suppression to $\mathrm{T}$, $\mathrm{V}$ still elicited suppression in context B. The present pattern of results (i.e., ABA renewal, but no ABC renewal) then can be explained by arguing that during conditioning configural context A-CS stimuli were formed and associated with the occurrence of the US. The loss of conditioned suppression to $\mathrm{T}$ on the first extinction trial and to $\mathrm{V}$ at the summation test then can be explained as generalization decrement from the acquisition stimuli.

An alternative explanation for the present results is that the switch from acquisition context A to extinction context $\mathrm{B}$ led participants to adopt the rule that suppression to $\mathrm{T}$ is only necessary in context $\mathrm{A}$. The adoption of such a rule would lead participants to demonstrate renewal of conditioned suppression when tested in $\mathrm{A}$, but not when tested in any other context. This notion then implies a comparative difference for the basis of a renewal effect in humans and animals. In other words, in animals renewal is controlled by a basic associative learning system, whereas in humans effortful capacity-limited cognitive processing may override the associative control of extinction. The question that arises is how to test such a hypothesis. Assuming that rule learning requires effortful cognitive processing one could attempt to replicate the present experiments adding a group of participants having to perform the same conditioned suppression task, but in addition instructed to simultaneously perform a cognitive distraction task. This cognitive task should interfere with rule learning and allow for more associative control of conditioned suppression of 
responding and the subsequent extinction of such conditioned suppression. Whether such a procedure does lead to the demonstration of $\mathrm{ABC}$ renewal, however, warrants further research.

\section{Implications for behavior therapy}

Although the present study found no evidence of the extinction context modulating extinguished behavior, the successful demonstration of the return of conditioned suppression with the ABA paradigm is nonetheless of particular importance for clinical research investigating the efficacy of cue exposure therapy in the treatment of abnormal behavior, such as anxiety disorders, eating disorders, and addictive behaviors (see Jansen, 1998). Learning theory constitutes the rationale of this form of treatment in which it is proposed that certain cues function as CSs eliciting cue reactivity conducive to the expression of abnormal behavior. For instance, when one considers alcoholism, it is argued that the perceptual characteristics of one's favorite drink become associated with the intake of alcohol (i.e., the effect of alcohol). These alcohol cues thus come to elicit conditioned alcohol responses, or alcohol cue reactivity, which consists of an increase in the subjective urge to drink alcohol and psychophysiological responses (e.g., changes in heart rate and skin conductance level). Such alcohol cue reactivity has been found to increase the likelihood of excessive drinking behavior (see Drummond, 2000). In cue exposure therapy, the alcoholic patient will be exposed to his favorite alcoholic drink, but he is prevented from actual drinking. At first, this will elicit a nearly irresistible urge to drink, but, with repeated exposure, this urge extinguishes. However, the present results clearly show that such extinction may be insufficient. Since not only a patient's favorite alcoholic drink, but also the environmental context in which the patient used to drink may serve as an alcohol CS, the extinguished cue-elicited urge to drink can reappear when the patient is exposed to his favorite alcoholic drink within the alcohol drinking context. Indeed, Conklin and Tiffany (2002) showed that although cue exposure therapy can lead to the successful extinction of drug cue reactivity, it does not prevent relapse of addictive behavior. This inefficacy of cue exposure therapy can be explained by a potential renewal effect. Corroborative evidence for such a view comes from a recent study by Collins and Brandon (2002) who found in social drinkers that subjective and psychophysiological alcohol cue reactivity can be renewed after cue exposure therapy when the alcohol cues are presented in a setting different from the treatment environment. These studies and the present results argue that extinction-based behavioral treatments of addiction (i.e., cue exposure therapy) will only prove to be beneficial when conducted within the environment in which the patient used to take drugs or alcohol (see also Havermans \& Jansen, 2003).

\section{References}

Arcediano, F., Ortega, N., \& Matute, H. (1996). A behavioural preparation for the study of human Pavlovian conditioning. Quarterly Journal of Experimental Psychology B, 49, 270-283. 
Bouton, M. E. (1993). Context, time and memory retrieval in the interference paradigms of Pavlovian learning. Psychological Bulletin, 114, 80-99.

Bouton, M. E. (1994a). Context, ambiguity, and classical conditioning. Current Directions in Psychological Science, 3, 49-53.

Bouton, M. E. (1994b). Conditioning, remembering, and forgetting. Journal of Experimental Psychology: Animal Behavior Processes, 20, 219-231.

Bouton, M. E., \& Bolles, R. C. (1979). Contextual control of the extinction of conditioned fear. Learning and Motivation, 10, 445-466.

Bouton, M. E., \& Peck, C. A. (1989). Context effects on conditioning, extinction, and reinstatement in an appetitive conditioning preparation. Animal Learning and Behavior, 17, 188-198.

Bouton, M. E., \& Swartzentruber, D. (1991). Sources of relapse after extinction in Pavlovian and instrumental learning. Clinical Psychology Review, 11, 123-140.

Collins, B. N., \& Brandon, T. H. (2002). Effects of extinction context and retrieval cues on alcohol cue reactivity among nonalcoholic drinkers. Journal of Consulting and Clinical Psychology, 70, 390-397.

Conklin, C. A., \& Tiffany, S. T. (2002). Applying extinction research and theory to cue-exposure addiction treatments. Addiction, 97, 155-167.

Drummond, D. C. (2000). What does cue-reactivity have to offer clinical research?. Addiction, 95(Suppl. 2), 129-144.

García-Gutiérrez, A., \& Rosas, J. M. (2003). Empirical and theoretical implications of additivity between reinstatement and renewal after interference in causal learning. Behavioural Processes, 63, 21-31.

Hall, G., \& Honey, R. C. (1990). Context-specific conditioning in the conditioned-emotional-response procedure. Journal of Experimental Psychology: Animal Behavior Processes, 16, 271-278.

Havermans, R. C., \& Jansen, A. (2003). Increasing the efficacy of cue exposure treatment in preventing relapse of addictive behavior. Addictive Behaviors, 28, 989-994.

Jansen, A. (1998). A learning model of binge eating: Cue reactivity and cue exposure. Behaviour Research and Therapy, 36, 257-272.

Kamin, L. J. (1969). Predictability, surprise, attention and conditioning. In B. A. Campbell \& R. Church (Eds.), Punishment and aversive behavior (pp. 279-296). New York: Apple-Century-Crofts.

Maes, J. H. R., Havermans, R. C., \& Vossen, J. M. H. (2000). Factors affecting context specificity of appetitive conditioned responding. Behavioural Processes, 48, 149-157.

Matute, H., \& Pineño, O. (1998). Stimulus competition in the absence of compound conditioning. Animal Learning and Behavior, 26, 3-14.

Pearce, J. M. (1987). A model for stimulus generalization in Pavlovian conditioning. Psychological Review, $94,61-73$.

Pineño, O., \& Matute, H. (2000). Interference in human predictive learning when associations share a common element. International Journal of Comparative Psychology, 13, 16-33.

Rescorla, R. A. (2001). Experimental extinction. In R. R. Mowrer \& S. B. Klein (Eds.), Handbook of contemporary learning theories (pp. 119-154). Mahwah, NJ: Erlbaum.

Rescorla, R. A., \& Wagner, A. R. (1972). A theory of Pavlovian conditioning: Variations in the effectiveness of reinforcement and nonreinforcement. In A. Black \& W. F. Prokasy (Eds.), Classical conditioning II (pp. 64-99). New York: Apple-Century-Crofts.

Thomas, B. L., Larsen, N., \& Ayres, J. J. B. (2003). Role of context similarity in ABA, ABC, and AAB renewal paradigms: Implications for theories of renewal and for treating human phobias. Learning and Motivation, 34, 410-436. 